\title{
Time Management of Non-Profit Sector Managers in the Context of Globalization
}

\author{
Emilia Gresakova ${ }^{1, *}$, and Darina Chlebikova ${ }^{1}$ \\ ${ }^{1}$ University of Zilina, Faculty of Operation and Economics of Transport and Communications, \\ Department of Economics, Univerzitna 1, 01026 Zilina, Slovakia
}

\begin{abstract}
.
Research background: The article deals with the issue of manager's time management in the non-profit sector in Slovakia in the conditions of the globalization. We verified the dependence through hypotheses that we established for each of the factors according to empirical studies, in which the impact on work organization and time management on managers was identified. Factors of time management according to reliability represented setting goals and priorities, using time management techniques, organizing work and workspace, and controlling one's own time.

Purpose of the article: The aim of the article is to point out the influence of time management on managers. We evaluate this impact in relation to stress reactions such as work-related stress and the manifestation of somatic symptoms, but also positive effects in the form of increased job satisfaction and better evaluation of work performance.

Methods: We evaluated the qualitative data by creating Contingency Tables, which served as a basis for testing dependence with Pearson's $\chi^{2}$ independence test or Fisher's exact test. The intensity of the dependence was determined by the most used Cramer coefficient.

Findings \& Value added: The results point to the dependence of individual time management factors on the areas of impact in the form of work-related stress, the emergence of somatic symptoms, job satisfaction and subjective evaluation of managers' work performance. In the discussion, in the context of globalization, we compared the views of the authors of the issue with our results and we tried to point out the possibilities and measures that could be applied in the findings.
\end{abstract}

Keywords: Time management; Globalization; Non-profit organizations; Work of managers; Stressors

JEL Classification: $J$ 59; L 31

\footnotetext{
* Corresponding author: emilia.gresakova@,fpedas.uniza.sk
} 


\section{Introduction}

Time management has been described using many different terms, including spontaneity, balance, flexibility, and time control [1]. However, some authors associated time management with a habit developed only by the determination and practice such as prioritizing and adhering to Soucie's priorities and setting priorities and planning tasks. Time management can also be considered as a process by which the individual fulfills the tasks and goals more effectively.

It is the process by which an individual gains control over the timing and content of what [2] does, and the way in which this can be achieved with the time available to us [3]. According to [4] time management involves determining which events are most important and recognizing that further activities will need to be planned around them (prioritization), deciding on duration (time estimation), adapting to unexpected situations (estimating unplanned situations). ), regular reassessment of objectives and priorities (evaluation) and adherence to them (observation of behavioral trends).

According to [5], the time dimension of work has become increasingly important due to the widening global dimension of competition and the increased demands for immediate availability of products 10 and services. [6] pointed to an increased pace of life, which is reflected in faster performance (acceleration), reduced time costs (eg eating faster, less sleep) and compression activities (lunch telephony). This is a way to gain insight into the use of time by managers and focusing on techniques for saving the time available to perform managerial activities by eliminating internal and external influences on the work of managers.

Time is a multidisciplinary phenomenon that is an essential part of the wider spectrum of scientific fields, shows the core of several scientific principles, in the plane physical and biological relationships. With its measurability and at the same time abstraction flow affects the daily human existence. Through measuring and monitoring time, we shape the rhythm of daily activities that involve satisfying elementary existential needs. The aspect of time directs the performance and the activities of individuals and groups in relation to society [7].

By organizing time and its appropriate use, we form the basis of the optimal lifestyle that takes into account work responsibilities, but at the same time gives enough space to relax in free time. Appropriate distribution of the time frame between necessary daily activities can be prevented by the negative phenomena that accompany current society stress, depression, or inability to overcome crisis situations. Importance time management in private and professional life is associated with optimal organization of activities and setting priorities [8].

In the field of work for managers, time management is an integral part prerequisite for systematic and effective coordination of management activities. Management is the process of leading and directing all or part of an enterprise through deployment and resource manipulation. The manager who is the bearer of the activities of this process is in the role informant and representative for subordinates, as well as the general public and therefore has the number of activities that need to be carried out, the justified importance of organizing time appropriately [9].

In this work, we focused on determining the impact of time management on managers. We examined these effects through the two main tools of the course in the field time management and time management behavior scales. In this work we determined research questions, which we used to determine what effect and with what intensity they have individual factors of time management of work - induced stress, origin and manifestation of static symptoms, but also positive impact factors such as job satisfaction and improvement 
subjective evaluation of performance. Hypotheses, we verified through Pearsonovho $\chi^{2}$ independence test and Fisher's exact test.

\section{Methods}

In the article, we used the questionnaire method for the purposes of the survey. The questionnaire was compiled by updating and adapting questions from the most relevant surveys in the field from renowned scientists and was divided into two parts. The first part dealt with the characteristics of the respondents. The second part focused on individual factors of time management as well as the impacts on inefficient use of one's own time. The first four factors focused on monitoring time management through TMBS [10].

These factors represent the most crucial areas of time management: setting goals and priorities (10 items), time management techniques (11 items), work organization and workspace ( 8 items) and perceived time control (5 items). The fifth factor focused on the tensions caused by the work of JIT ( 6 items), which describes the degree of perception of pressure and frustration of managers stemming from their work, which is growing by the inadequate approach to time management [11]. The sixth factor concerned the somatic symptoms of SSRS (5 items), where we focused on identifying the four most well-known symptoms in the work of a manager according to a study by [12] and left one question open for managers to supplement their own symptoms. The seventh factor focused on satisfaction from the work of the JDS (3 items). This factor focuses on the diagnosis of work in terms of general job satisfaction [13] and the last factor is the evaluation of JPS work performance (5 items), which focuses on quality, quantity, cooperation, reliability and general evaluation.

We evaluated the qualitative data by creating Contingency Tables, which served as a basis for testing dependence with Pearson's $\chi 2$ independence test or Fisher's exact test. The intensity of the dependence was determined by the most used Cramer coefficient. Pearsonov $\chi^{2}$ the test of independence of two variables is based on contingency tables of these features of the actual and theoretical abundances of the individual combinations occurrence of character values. In practice, it has expanded mainly for dependency verification qualitative characteristics. The basic idea of the independence test is a comparison to observed empirical abundances and assuming the validity of the null hypothesis expected theoretical frequencies. According to the value of the test statistics, we determine $\mathrm{p}$-value and compare it with the selected level of significance. If the theoretical abundance, which assume independence, "very" differ from the observed frequencies, the value test statistics will be large and the null hypothesis must be rejected. We use Fisher's exact test in the work, provided that they are not met Pearson conditions $\chi^{2}$ independence test. It is a test of statistical significance used in the analysis of contingency tables. Although used in practice when the sample sizes are small, applies to all sample sizes. It is named after its inventor Ronald Fisher and is one of a class of accurate tests because of the significance of the deviation from the null hypothesis can be calculated exactly as we should rely on approximation. We verified the intensity of these dependencies through Cramer's coefficient that comes from the interval $<0 ; 1>$. Its value indicates the dependence between monitored characters [14].

\section{Results}

In the first research question, we focused on finding out what effect it has from completing a course in time management on the factors of the TMBS scale. TMBS scale we used, not only because it proved itself in the comparison of individual scales through the highest 
value of individual factors using the Cronbach's alpha. Cronbach's alpha is typically used in questionnaires where items are scaled. A Cronbach's alpha value $\geq 0.80$ is considered the optimal value for comparison groups. For tools with a smaller number of items, a value in the range from is accepted $0.60-0.80$ [15]. For all 4 factors, our scale represented a value of 0.83 , which represents optimal value. However, we used this scale because according to it is time management perceived as the behavior of time composed of three main dimensions. The first dimension is awareness of the past, present and future; this assumption includes self-awareness of the use of time with respect to affect and knowledge, as well as acceptance activities and responsibilities relating to the limitation of an individual's ability to act in time. This dimension can be referred to as time assessment of behavior [16].

The second dimension it consists of the techniques and tools themselves that aim to provide space for better organization of tasks over time. These include setting goals, priorities, creating lists, and grouping of activities. This dimension can be called planning behavior. The third dimension concerns structures that facilitate time management by providing feedback on ongoing activities and the limitations that arise in their exercise. This dimension is called monitoring behavior.

Hypothesis testing is preceded by finding out the actual number of qualitative variables (completion of the course and averages of TMBS factor responses). Using contingency tables, we calculate the theoretical frequencies and test the fulfillment of the set conditions for the calculated theoretical frequencies. The condition for creating a contingency table was knowledge of two qualitative variables of each manager. The first categorical variable in the first research question is the completion of a course in time management, where managers only had to say yes or 23 no. The second categorical variable represents the average for a specific factor of the TMBS scale; in the case of evaluating the first hypothesis, it is a factor for setting goals and priorities, which we evaluate equally for each of the factors separately.

Table 1. Summary of the results of the hypotheses for the 1st research question.

\begin{tabular}{|l|c|c|c|c|}
\hline Hypotheses for the 1st research question & Sig. & $\begin{array}{c}\text { Accepted } \\
\text { / Rejected }\end{array}$ & $\begin{array}{c}\text { Cramer } \\
\text { coefficient }\end{array}$ & $\begin{array}{c}\text { Degree of } \\
\text { significance }\end{array}$ \\
\hline $\begin{array}{l}\text { H1: There is a relationship between } \\
\text { completing a course in time management }\end{array}$ & 0.167 & rejected & - & - \\
\hline $\begin{array}{l}\text { H2: There is a relationship between } \\
\text { completing a course in time management }\end{array}$ & 0.001 & accepted & 0.217 & $\begin{array}{c}\text { weak } \\
\text { dependency }\end{array}$ \\
\hline $\begin{array}{l}\text { H3: There is a dependence between } \\
\text { completing a course in time management }\end{array}$ & 0.004 & accepted & 0,200 & $\begin{array}{c}\text { teak } \\
\text { dependency }\end{array}$ \\
\hline
\end{tabular}

If the dependence was confirmed, we further determined its significance using Cramer's $\mathrm{V}$, from which we derived the degree of intensity of the contingency of variables. However, the contingency rate appeared weak in both cases of confirmed alternative hypotheses.

The second research question examined the effect of completing a course in time management on impact factors. 
Table 2. Summary of the results of the hypotheses for the 2 nd research question.

\begin{tabular}{|l|c|c|c|c|}
\hline Hypotheses for the 2nd research question & Sig. & $\begin{array}{c}\text { Accepted } \\
\text { / Rejected }\end{array}$ & $\begin{array}{c}\text { Cramer } \\
\text { coefficient }\end{array}$ & $\begin{array}{c}\text { Degree of } \\
\text { significance }\end{array}$ \\
\hline $\begin{array}{l}\text { H4: There is a relationship between } \\
\text { completing a course in time management }\end{array}$ & 0.129 & rejected & - & - \\
\hline $\begin{array}{l}\text { H5: There is a relationship between } \\
\text { completing a course in time management }\end{array}$ & 0.001 & rejected & 0.217 & $\begin{array}{c}\text { weak } \\
\text { dependency }\end{array}$ \\
\hline
\end{tabular}

It was assumed that the cause of the changes on individual impacts: work-related stress, the occurrence of somatic symptoms, will be the completion of a course in time management. However, this was not reflected in any of the impact factors, see Table 2.

It is clear from the table that there is a dependence between the various factors of the scale in the field of time management. The degree of contingency did not only manifest itself in the areas between setting objectives and priorities and time control, and between the use of time management and time control techniques.

Table 3. Provides an evaluation of the hypotheses for the third research question.

\begin{tabular}{|l|l|l|c|l|}
\hline Hypotheses for the 3rd research question & Sig. & $\begin{array}{c}\text { Accepted } \\
\text { / Rejected }\end{array}$ & $\begin{array}{c}\text { Cramer } \\
\text { coefficient }\end{array}$ & $\begin{array}{c}\text { Degree of } \\
\text { significance }\end{array}$ \\
\hline $\begin{array}{l}\text { H6: There is a relationship between the } \\
\text { ability to set goals and priorities and the use }\end{array}$ & 0.000 & accepted & 0.349 & $\begin{array}{l}\text { moderate } \\
\text { dependence }\end{array}$ \\
\hline $\begin{array}{l}\text { H7: There is a relationship between setting } \\
\text { goals and organizing the work and work }\end{array}$ & 0.001 & accepted & 0.251 & $\begin{array}{l}\text { weak } \\
\text { dependency }\end{array}$ \\
\hline $\begin{array}{l}\text { H8: There is a relationship between the use } \\
\text { of TM techniques and the organization of }\end{array}$ & 0,000 & acceped & 0.238 & $\begin{array}{l}\text { weak } \\
\text { dependency }\end{array}$ \\
\hline
\end{tabular}

The causality in the conclusions from the third research question should point to the dependence of individual TMBS factors on each other. In the case of the first hypothesis, it was confirmed to us that the ability to set goals and priorities is really dependent on the use of time management techniques, which has been demonstrated in the intensity of dependence. Furthermore, we can state that the ability to set goals and priorities also depends on the organization of work and work space. Managers who know how to set goals and priorities can also organize their work and their workspace.

\section{Discussion}

The fact that there was no dependence between completing the course in time management and petting goals and priorities and perceived control over their time means that completion of the course does not affect the ability to set goals and priorities and perceived control of time managers. The subject of further research could be within the findings. Find addictions with just these two factors and reveal what affects them the ability to set goals and priorities and monitor their actual spending of time [17].

In the second research question, we found a limitation that offers the posibility better capture of the area by specifying a course in the area. Managers could take a course in selfmanagement or courses in personality growth, which marginally discussed the issue of time management. The subject of further research could be the monitoring of individual factors in a relationship to individual courses. At the same time, the effectiveness of individual courses could be tested depending on the time that elapses since their completion. This 
would tell if One-off courses are sufficient or regular individual habits are neceséry support through further training in time management. Alternatively, we suggest measure the effectiveness of individual courses in relation to demographics and thus know apply a specific course with customized kontent [18].

The conclusions of the third research question show that despite the confirmed dependence there is no dependence between the factors of time management on the perception factor of control over at their own time This factor could be closely related to the loss of time in the form stressors and distractions. We therefore propose to monitor addiction in future research between internal and external factors that affect work and time control in order to the impact and occurrence of these restrictions can be clearly identified. Dependence was not confirmed even within the first factor of the behavioral scale in the field of time management and work-related stress, while it has been confirmed in a relationship to the onset and manifestation of somatic symptoms. This result is interesting as it is work-related stress, according to previous studies, prevents onset and manifestation somatic symptoms. In connection with the given finding, there is room for monitoring from which level of manifestation of somatic symptoms would be demonstrated significant dependence on setting goals and priorities. From what point of speech managers they feel the need to improve the setting of objectives and priorities [19].

Future research could also address the issue of comparing traditional ones tools, new tools and software platform in connection with the use. At the same time we suggested making an overview of the tools that are attractive depending on the focus business entities. The latest proposal in the field of future research is from our parties to find a tool that would be usable depending on the characteristics of each typologies of personalities [20].

This is paper is an outcome of project VEGA: 1/0544/19 Formation of the methodological platform to measure and assess the effectiveness and financial status of non-profit organizations in the Slovak Republic.

\section{References}

1. Lakein, A. (1973). How to Get Control of your Time and Life. New York: Nal Penguin Inc.

2. Richards, J.H. (1987). Time management - a review. Work \& Stress, 1(1), pp. 73-78.

3. Jordan, C., Cobb, N., McCully, R. (1989). Clinical issues of the dual-career couple. Social Work, 34(1), 29-32.

4. Schuler, R. S. (1979). Managing stress means managing time. Personnel Journal, 58(12), 851-854.

5. Orlikowsky, W.J., Yates, J. (2002). Its about time: temporal structuring in organizations. Organization Science, 13, pp. 684-700.

6. Garhammer, M. (2002). Pace of life and enjoyment of life. Journal of Happiness Studies, 3, pp. 217-256.

7. Macan, T.H., Shahani, C., Dipboye, R.L., Philips, A.P. (1990). College students time management: correlations with academic performance and stress. Journal of Educational Psychology, 82(4), 760-768.

8. Macan, T. H. (1994). Time management: Test of a process model. Journal of Applied Psychology, 79(3), 381-391.

9. Macan, T.H. (1996). Time-management training: effects on time behaviours, attitudes, and job performance. The Journal of Psychology, 130(3), 229-236. 
10. Mackenzie, R. A. (1975). New time management methods for you and your staff. Chicago, IL: The Dartnell Corporation.

11. Mackenzie, R. A. (1990). The time trap. New York: Amacom.

12. Mackenzie, R.A. (1972). The Time Trap: Managing your Way Out. New York: Amacom.

13. Mudrack, P. (1997). The structure of perceptions of time. Educational and Psychological Measurement, 57(2), pp. 222-240.

14. Onacken, W. Jr., Wass, D. L. (1985). Management time: Who's got the monkey? Harvard Business Review, 77(6), 178-+

15. Jex, S. M., Elacqua, T. C. (1999). Time management as a moderator of relations between stressors and employee strain. Work and Stress, 13(2), 182-191.

16. Hofmann, W. Baumeister, R.F. Forster, G. Vohs, K. (2012). Everyday Temptations: An Experience Sampling Study od Desire, Conflict and Self-Control. Journal of Personality and Social Psyhology, 103(6), 1318-1335.

17. Francis-Smythe, J.A. and Robertson, I.T. (1999b). Time-related individual differences. Time \& Society, 8(2), pp. 273-292.

18. Green, P. and Skinner, D. (2005). Does time management training work: an evaluation. International Journal of Training and Development, 9(2), 124-139.

19. Sakelaris, T.L. (1999). Effects of Self-managed Study Skills Intervention on Homework and Academic Performance of Middle School Students with Attention Deficit Hyperactivity Disorder, University of Oregon, Eugene, OR.

20. Smith, T.D., Hughes, K., Dejoy, D. M., Dyal, M-A. (2018). Assessment of relationships between workstress, work-family conflict, burn out and firefighter safety behavior out comes. Safety science, 103, 287- 292. 